\title{
An Intra-tendonous ganglion cyst causing impingement between the anterior cruciate ligament and anterior root of the medial meniscus: a case report
}

\author{
Mei Guolong ${ }^{\dagger}$, Gao Zhi ${ }^{\dagger}$ and Hu Yong
}

Background: There are several reports of symptomatic ganglion cysts near the anterior cruciate ligament $(\mathrm{ACL})$, posterior cruciate ligament $(\mathrm{PCL})$, and lateral and medial meniscus, but symptomatic ganglia arising from the anterior horn of the medial meniscus to the ACL have not been reported. Here we report the arthroscopic resection of a ganglion cyst arising from the anterior horn of the medial meniscus with a meniscal tear to the ACL.

Case presentation: A 43-year-old female presented with a 10-year history of continuous aching pain in the right knee, but without any history of trauma. Clinical examination revealed right-sided knee pain in the medial joint line, exacerbated by end range flexion and extension, a $-10^{\circ}-100^{\circ}$ active range of movement, and $a-5^{\circ}-110^{\circ}$ passive range of movement. McMurray's, patellar compression, and compression rotation tests were positive. Magnetic resonance imaging (MRI) and arthroscopic examination revealed a cyst related to the $A C L$ and medial meniscus. Histological examination confirmed the cyst to be a ganglion cyst.

Conclusions: We present a new type of ganglion cyst, this is the first reported case of an ganglion cyst impinged between the $A C L$ and the medial meniscus. It is hoped that this study will provide a better understanding of the condition and lead to better diagnosis and treatment.

Keywords: Ganglion cyst, Anterior cruciate ligament, Medial meniscus

\section{Background}

Since Caan first reported, in a 1924 autopsy, a ganglion cyst on the anterior cruciate ligament [1], more and more ganglion cysts around the knee have been reported [2-4], the common sites of cysticlesions of knee joint is the ACL followed by PCL, and then menisci, especially medial meniscus; other rare sites are infrapatellar pad of fat, medial plica and popliteus tendon [5]. A ganglion cyst is often defined as a cyst swelling that is formed of myxiod matrix, which can lead to cystic lesions associated with a joint or tendon sheath $[6,7]$. No reports have yet appeared concerning a symptomatic ganglion impingement between the ACL and medial meniscus. We report a case of a symptomatic ganglion cyst that originated from

\footnotetext{
* Correspondence: yhoo0425vip@sina.com

${ }^{\dagger}$ Equal contributors

Department of arthroscope, Sichuan orthopeadic Hospital Chengdu, Sichuan 610000, China
}

the anterior horn of the medial meniscus and extended to the ACL.

\section{Case presentation}

A-43-year-old female presented with a 10-year history of right knee pain of insidious onset. The problem began as an aching pain, had worsened in last 10 days, and was particularly noticeable when standing after squatting and while going up and down the stairs. The patient reported no history of trauma and no previous knee problems. She was $158 \mathrm{~cm}$ tall and $64 \mathrm{~kg}$ in body weight.

Physical examination revealed right-sided knee pain in the medial joint line, exacerbated by end range flexion and extension, and without swelling or bruising. No mass was palpable around the knee. The active range of movement was $-10^{\circ}-100^{\circ}$, and passive range of movement was $-5^{\circ}-110^{\circ}$. Atrophy of the right quadriceps was present. Anterior and posterior drawer and Lachmann tests were found to be negative, but the McMurray's test,
C Biomed Central

(C) 2013 Guolong et al.; licensee BioMed Central Ltd. This is an open access article distributed under the terms of the Creative Commons Attribution License (http://creativecommons.org/licenses/by/2.0), which permits unrestricted use, distribution, and reproduction in any medium, provided the original work is properly cited. 

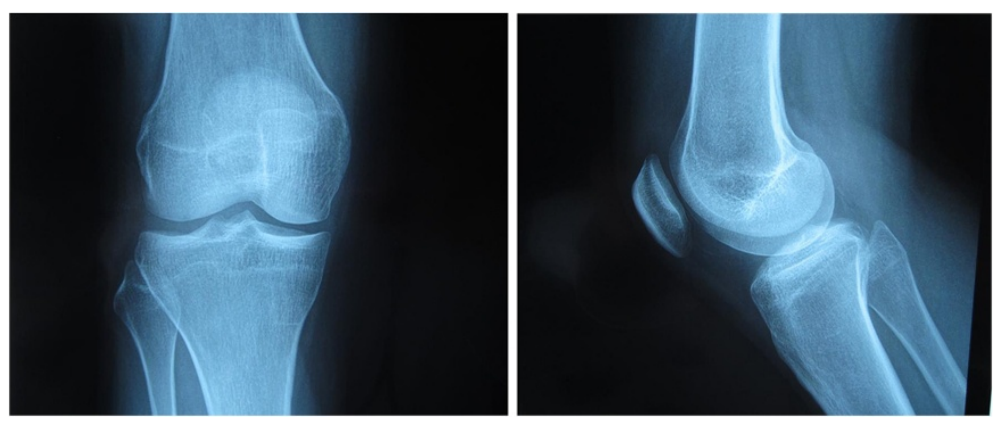

Figure 1 Plain film radiograph of the anterior-posterior and lateral right knee show no abnormalities or loose bodies.

patellar compression test, and compression rotation test were positive. Plain film radiographs of the knee were performed and displayed no bone abnormalities or loose bodies (Figure 1).

An MRI revealed a grade 3 horizontal tear, according to Mink's classification of the anterior segment of the medial meniscus, and a multi-lobulated cyst arising from the anterior horn of the medial meniscus to the lateral region of the anterior cruciate ligament (ACL) (Figure 2).

Arthroscopic surgery was performed under general anesthesia and a tourniquet was used. We shaved the cyst only without ACL reconstruction, and at the same time, we repaired the tear in the meniscus. The knee was flexed at a 90 degree angle, on the operating table, using a foot stopper. The ACL, PCL, and also both lateral and medial menisci were intact under arthroscopic examination. There was no evidence of neoplasia, and arthroscopy revealed both medial menisci were intact and cartilage was normal. A horizontal tear was located in the anterior segment of the medial meniscus (Figure 3) and a cyst arose from the anterior horn of the medial meniscus to the lateral region of the ACL (Figure 4).

A histological examination of the resected cyst wall, by three pathologists, confirmed the cyst diagnosis. On hematoxylin-and-eosin staining, we can found a fibrouswalled, ganglion cyst associated with fatty cells (Figure 5).
Following surgery, the patient had an uneventful postoperative period, was able to return to her job within 3 weeks, and had no complaints. After the operation, the active range of movement was $-0^{\circ}-120^{\circ}$, and an MRI examination 6 months post-operative revealed that the ACL and meniscal cyst had disappeared. The patient's pain also disappeared completely during the 3-year follow-up period.

\section{Discussion}

There are several reports of symptomatic ganglion cysts near the anterior cruciate ligament, posterior cruciate ligament, and lateral and medial menisci $[8,9]$. In particular, we did not find any reports of a symptomatic ganglion originating from the anterior root of the MM to the ACL.

The aetiology of ganglion cysts is unknown. Mucoid degeneration of collagen and connective tissues is widely used to explain the formation of cysts. In addition,trauma or tissue irritation, herniation of the synovium, displacement of synovial tissue during embryogenesis, and proliferating pluripotential messenchymal cells are often thought to cause the cysts [10]. Bergin et al. report that ACL ganglia and mucoid degeneration commonly coexist, and gave some evidence to suggest these two entities may share a similar pathogenesis [11]. In our case, the excised specimen was derived from the MM and ACL, and the cyst had the same organizational structure as a ganglion cyst. We also
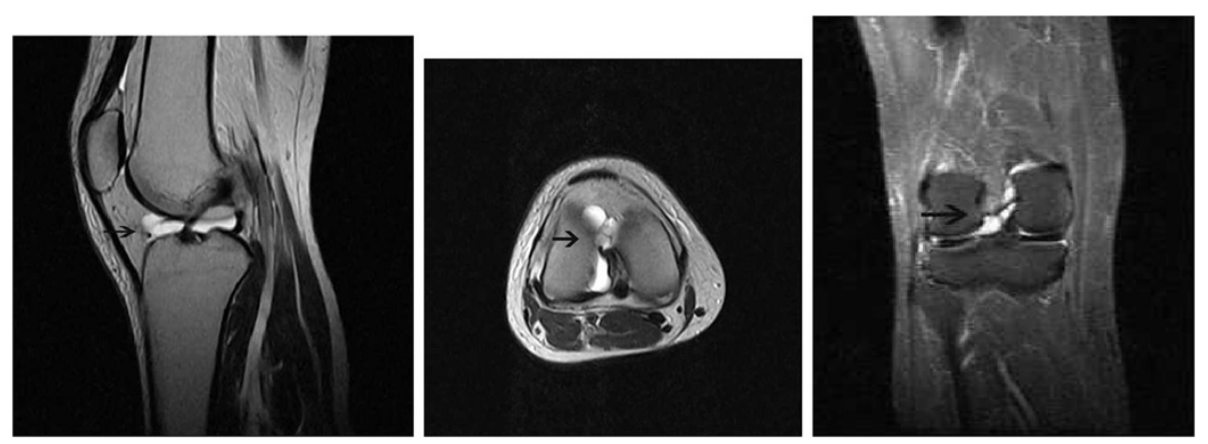

Figure 2 T2-weighted MRI images of the right knee show the multi-lobulated cyst arising from the anterior horn of the medial meniscus to the lateral region of anterior cruciate ligament (black arrow). 


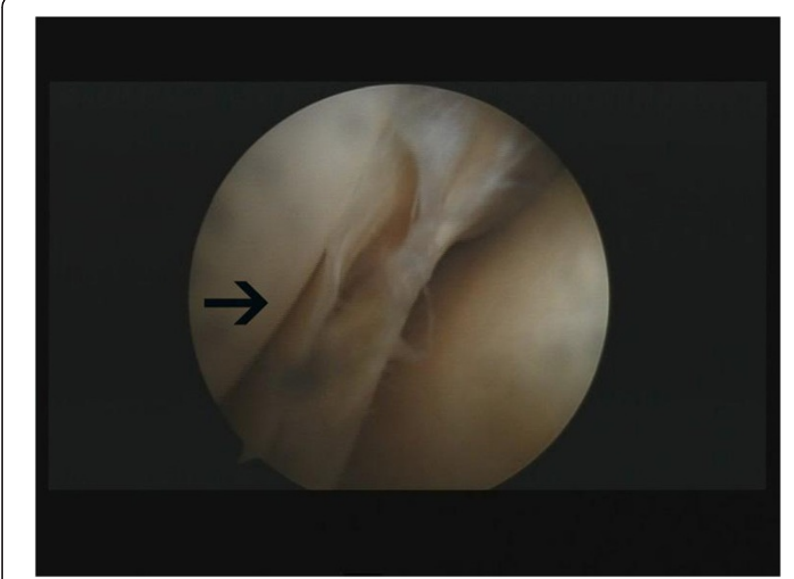

Figure 3 A horizontal tear was located in the anterior segment of the medial meniscus (black arrow).

observed the degradation of meniscus tissue, suggesting that the mucoid degeneration and chronic trauma as a result of the meniscus tear could possibly explain the origin of our cyst.

Occasionally, the clinical manifestation of a cyst is largely dependent on the pathologic process involved, along with its location, size, mass effect, and relationship to surrounding structures [12]. In this case, a preoperative diagnosis was difficult due to a lack of clear signs and symptoms leading to this disease. Therefore, we required that an MRI and arthroscopy be undertaken [13-15]. A diminished range of movement (ROM) is often described as a typical clinical manifestation. In our case, the patent revealed an active range of movement of $-10^{\circ}-100^{\circ}$, and a passive range of movement of $-5^{\circ}-110^{\circ}$. We removed the torn area of the meniscus by arthroscopic surgery, and restored full ROM.

The anterior horn of the MM is attached to the side of ACL anatomically, and provides the anatomical basis for the emergence of this special cyst. Including cyst impingement between the PCL and MM, there have been no reports regarding the primitive appearance, location, and sequence of the cyst, whether cyst initiation happens in the ACL whether it invades in the anterior root of the $\mathrm{MM}$, or on the contrary. In our case, the patient had a

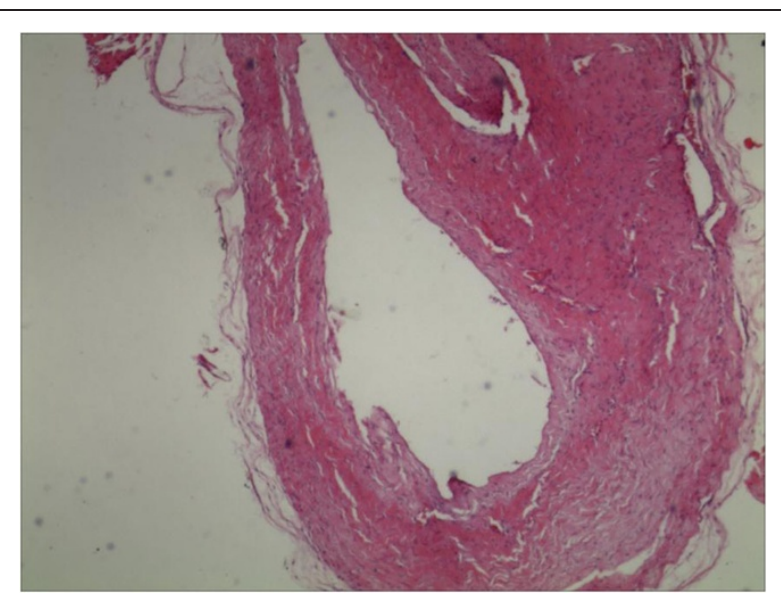

Figure 5 Histologic section of cyst material showing the ganglion cyst. (Stain, hematoxylin and eosin, original magnification $\times 20$ ).

horizontal tear located in the anterior segment of the medial meniscus. Relationships exist between cysts and meniscus tears. Barrie [16] found that the menisci cyst was associated with tears, either primarily horizontal or with a horizontal component. Tracks were often demonstrable leading from the tear to the cyst. The relationship of cysts to "myxoid" change of the meniscus is discussed. This suggests that in our instance, the ganglion cyst is maybe produced first at the anterior horn of the MM, then incurs into the ACL. And surgical repair of the meniscus avulsion and restoration of the anatomy and biomechanical function of menisci as early as possible will reduce the ACL lesion of this kind of cyst.

\section{Conclusion}

The ganglion cyst on the ACL can be caused by injury of the anterior horn of the meniscus and on the premise of guarantee the stability of the knee joint, A surgery limited on the meniscus can solve the problem in the early time.

\section{Consent}

Written informed consent was obtained from the patient for publication of this case report and any accompanying image. A copy of the written consent is available for review by the Editor-in-Chief of this journal.

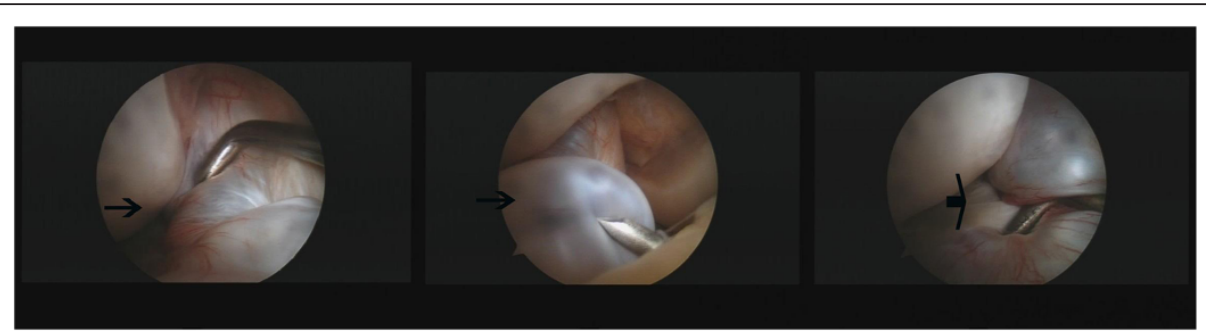

Figure 4 A cyst arising from the anterior horn of the medial meniscus to the lateral region of anterior cruciate ligament (black arrow). 


\section{Competing interests}

The authors declare that they have no competing interests.

\section{Authors' contributions}

MG and HY carried out the surgical treatment, GZ discussed the results and commented on the manuscript. All authors have read and approved the final manuscript.

\section{Acknowledgments}

The work was supported by the Program arthroscope Research of Development Fund of the Sichuan orthopeadic Hospital.

Received: 14 November 2012 Accepted: 4 October 2013

Published: 17 October 2013

\section{References}

1. Noda M, Kurosaka M, Maeno K, et al: Ganglion cysts of the bilateral cruciate ligament. Arthroscopy 1999, 15(8):867-870.

2. Ahmed F, Ibrahim SA, Soliman A, et al: Ganglion cyst of the posterior cruciate ligament. BMJ Case Reports 2010, 2010:1-4.

3. Yong Bum J, Young Mo K, et al: Symptomatic posterior cruciate ganglion cyst causing impingement between posterior root of the medial meniscus and anterior to the posterior cruciate ligament. Knee Surg Relat Res 2012, 24(1):52-55.

4. Christer R, Watson TP: Case report: intra-tendinous ganglion of the anterior cruciateligament in a young footballer. J Orthopaedic Surg Res 2006, 1:11.

5. Kang CN, Kim DW, Kim DJ, et al: Intra-articular ganglion cysts of the knee. Arthroscopy 1999, 15:373-378.

6. Underwood JCE, Hunter J: Underwood JCE General and systemic pathology. Edinburgh: Churchill Livingstone; 2004.

7. Nikolopoulos I, Krinas G, Kipriadis D, et al: Large infrapatellar ganglionic cyst of the knee fat pad: a case report and review of the literature. $J$ med Case Reports 2011, 5:351.

8. Durante JA: Ganglion cyst on the posterior cruciate ligament: a case report. JCCA 2009, 53(4):334-338.

9. Ohishi T, Torikai E, Suzuki D, et al: Arthroscopic treatment of a medial meniscal cyst using a posterior trans-septal approach: a case report; sports medicine, arthroscopy, rehabilitation, therapy \& technology. 2010, 2010(2):25.

10. Kim R, Kim K, Lee J, et al: Ganglion cysts of the posterior cruciate ligament. Arthroscopy 2003, 19(6):e41-e45.

11. Bergin D, Morrison WB, Carrino JA, et al: Anterior cruciate ligament ganglia and mucoid degeneration:coexistence and clinical correlation. AJR Am J Roentgenol 2004, 182(5):1283-1287.

12. Beall DP, Ly JQ, Wolff JD, et al: Cystic masses of the knee: magnetic resonance imaging findings. Curr Probl Diagn Radiol 2005, 34:143-159.

13. Seki $K$, Mine $T$, Tanaka $H$, et al: Locked knee caused by intra-articular ganglion. Knee Surg Sports Traumatol Arthrosc 2006, 12:859-861.

14. Tyrrell PM, Pullicino VN, McCall IW: Intra-articular ganglion cysts of the cruciate ligament. Euro Radio 2000, 10:1233-1238.

15. Zachazewski JE, Magee DJ, Quillen WS: Athletic injuries and rehabilitation. Philadelphia: W.B Saunders Company; 1996.

16. Barrie HJ: The pathogenesis and significance of menisceal cysts. J Bone Joint surg Br 1979, 61-B(2):184-189.

\section{doi:10.1186/2052-1847-5-22}

Cite this article as: Guolong et al: An Intra-tendonous ganglion cyst causing impingement between the anterior cruciate ligament and anterior root of the medial meniscus: a case report. BMC Sports Science, Medicine, and Rehabilitation 2013 5:22.

\section{Submit your next manuscript to BioMed Central and take full advantage of:}

- Convenient online submission

- Thorough peer review

- No space constraints or color figure charges

- Immediate publication on acceptance

- Inclusion in PubMed, CAS, Scopus and Google Scholar

- Research which is freely available for redistribution

Submit your manuscript at www.biomedcentral.com/submit 